\title{
Community Structure and Quantification of Nitrifying Bacteria in Integrated Fixed Film Activated Sludge System Treating Industrial Wastewater
}

\author{
Chao Li*, Weili Xi and Tao Bi \\ Tianjin Eco-city Environmental Technology Consulting Ltd., China \\ ${ }^{*}$ Corresponding author
}

\begin{abstract}
To reveal the community structure and abundance of ammonia-oxidizing bacterial (AOB) and nitrite-oxidizing bacterial (NOB) in integrated fixed film activated sludge process (IFAS) treating industrial wastewater, the molecular biological techniques of polymerase chain reaction denaturing gradient gel electrophoresis (PCR-DGGE), cloning and sequencing and realtime quantitative PCR were applied. DGGE results showed that in the process of the experiment, the dominant species of suspended sludge and biofilm were different and that some kinds of populations had been highly preponderance consistently. Additionally, variation in influents had no significant effect on the distribution of the AOB and NOB communities. Sequencing analysis of screened clones revealed Nitrosospira sp. was the particular AOB population in suspended sludge, and some members of Nitrosomonas sp. are helpful to keep the biomass remained in the bio-carrier surface. Real-time PCR indicated that the proportion of the AOB and NOB in total amount of bacteria increased significantly after the domestication period. The AOB and NOB population in the suspended sludge were even higher than the content of the biofilm.
\end{abstract}

Keywords- IFAS; AOB; NOB; PCR-DGGE; real time PCR

\section{INTRODUCTION}

IFAS (also known as hybrid biological reactor) process is an increasingly popular modification of conventional activated sludge, in which bio-carriers are added to suspended growth reactors to provide attachment surfaces for biofilms, thereby increasing microbial concentrations and rates of contaminant degradation. Hence it has the advantages of both the suspended as well as attached growth systems [1]. IFAS is an attractive option for retrofitting many existing facilities, in part because the inclusion of an attached biomass phase enriches for the slow growing autotrophs responsible for ammonia and nitrite oxidation (nitrifying bacteria) [2], which are central to nitrogen removal processes in wastewater treatment, thus providing improved nitrification capacity without construction of new reactors.

Nitrification in IFAS is carried out by two different groups of organisms, AOB and NOB, respectively. AOB are primarily responsible for the first and often the rate-limiting step in nitrification: conversion of ammonia to nitrite [3]; NOB are responsible for the second step in nitrification: conversion of nitrite to nitrate. Aerobic autotrophic AOB are found within two phylogenetic groups based on comparative analyses of 16S rRNA sequences [4]. One group comprises strains of
Nitrosomonas and Nitrosospira within the class of $\beta$ Proteobacteria, and the other contains Nitrosococcus oceani and Nitrosococcus halophilus within the class of $\gamma$ Proteobacteria. NOB are also found within two phylogenetic groups: Nitrospira within the class of Nitrospira and Nitrobacter within the class of $\alpha$-Proteobacteria [5].

The physiological activity and abundance of $\mathrm{AOB}$ and NOB in suspended sludge and biofilm biomass is critical in the design and operation of IFAS, particularly since these organisms display low growth rate, and high sensitivity to environmental disturbances and inhibitors [6]. For this reason, a better understanding of the ecology and microbiology of $\mathrm{AOB}$ and NOB in IFAS is necessary to enhance treatment performance and control. However, most of the related studies have focused mainly on treatment performance and operation conditions without considering the $\mathrm{AOB}$ and $\mathrm{NOB}$ communities involved [1]. Although a few researchers have investigated bacterial communities of IFAS [5,7], the information on structure, diversity, and abundance of $\mathrm{AOB}$ and NOB communities in suspended sludge and biofilm of IFAS treating industrial wastewater is still largely limited.

DNA-based molecular biology techniques are valuable tools for the characterization of microbial diversity in biological wastewater treatment reactors such as IFAS. In particular, PCR-DGGE analysis has been developed as a highthroughput fingerprinting technology that can directly measure the genetic biodiversity of a sample. Coupled with sequencing and phylogenetic analysis, this method can provide an excellent overview of the microbial composition and diversity in a given system. Recently, real time-PCR techniques have enabled quantization of $\mathrm{AOB}$ and $\mathrm{NOB}$ populations in the environment because they combine high throughput with high analytical sensitivity and precision.

The goal of this research was to evaluate the diversity of AOB and NOB in both suspended sludge and biofilm biomass of IFAS treating industrial wastewater and to identify individual species within the $\mathrm{AOB}$ and $\mathrm{NOB}$ communities. The samples were analyzed by nested PCR-DGGE followed by cloning and sequencing of the $16 \mathrm{~S}$ rRNA genes. Finally, real-time quantitative PCR were conducted to determine the total bacterial concentrations and the proportion of $\mathrm{AOB}$ and NOB based on 16S rRNA. 


\section{MATERIALS AND MethODS}

\section{A. Description of IFAS System and Sampling}

The pilot IFAS system as well as the characteristics of the bio-carriers, wastewater and the seeded activated sludge used in the system had all been described in our previous research [8]. The system included an anaerobic, an anoxic and two aerobic reactors. Bio-carriers were fixed in both the aerobic reactors. Details of sampling and operational parameters were listed in Table 1.

TABLE I. DETAILS OF SAMPLING AND OPERATIONAL PARAMETERS

\begin{tabular}{|c|c|c|c|}
\hline $\begin{array}{l}\text { Sampling } \\
\text { time (d) }\end{array}$ & & $\begin{array}{c}\text { Suspended } \\
\text { sludge MLSS } \\
\text { (mg/L) }\end{array}$ & $\begin{array}{c}\text { Biofilm } \\
\text { biomass } \\
(\mathrm{mg} \cdot \mathrm{L})\end{array}$ \\
\hline 1 & $\begin{array}{c}\text { Inoculated sludge } \\
\mathrm{S}_{0}\end{array}$ & - & - \\
\hline 20 & Biofilm $\mathrm{A}_{1}$ & 0 & 680 \\
\hline 40 & Biofilm $\mathrm{A}_{2}$ & 0 & 1180 \\
\hline 80 & Biofilm $\mathrm{A}_{3}$ & \multirow{2}{*}{4930} & \multirow{2}{*}{2055} \\
\hline 80 & $\begin{array}{c}\text { Suspended sludge } \\
\mathrm{S}_{3} \\
\end{array}$ & & \\
\hline 120 & Biofilm $\mathrm{A}_{4}$ & \multirow[b]{2}{*}{3215} & \multirow[b]{2}{*}{2296} \\
\hline 120 & $\begin{array}{c}\text { Suspended sludge } \\
\mathrm{S}_{4} \\
\end{array}$ & & \\
\hline 150 & Biofilm $\mathrm{A}_{5}$ & \multirow[b]{2}{*}{3150} & \multirow[b]{2}{*}{2300} \\
\hline 150 & $\begin{array}{c}\text { Suspended sludge } \\
\mathrm{S}_{5}\end{array}$ & & \\
\hline
\end{tabular}

\section{B. DNA Extraction and Nested PCR}

Pretreatment and DNA extraction of sludge samples were conducted following the established method [8].

To amplify AOB and NOB specific $16 \mathrm{~S}$ rDNA for DGGE, a nested PCR approach was used. For the first round PCR, the AOB-specific primer pair was used to obtain DNA fragments $465 \mathrm{bp}$ in length with an equimolar mixture of three forward primers (CTO189fA/B and CTO189fC), and with the reverse primer CTO654r, containing a single ambiguous base. FGPS1269 and FGPS872 were used as the NOB-specific primer pair. A nested PCR was performed on the PCR products obtained from the first round with a second primer pair (F338GC/R518) allowing the amplification of an internal fragment of 196bp. All PCR amplicons were examined by electrophoresis in $1.5 \%(\mathrm{w} / \mathrm{v})$ agarose with GoldView (SBS Genetech Co., LTD, Beijing, China) staining to confirm the product size. All primers, target and PCR conditions are listed in Table 2.

\section{DGGE Analysis}

The nested PCR amplicons were separated on polyacrylamide gels $(8 \%, 37.5: 1$ acrylamide-bisacrylamide) with a $30-60 \%$ linear gradient of denaturant. The gel images were analyzed with the software Quantity One, (version 4.6.2, Bio-rad). The Shannon diversity index $H$ was introduced to examine the structural diversity of AOB and NOB community.

\section{Cloning and Sequencing}

Prominent DGGE bands were excised and purified by using a PolyGel Extraction Kit for cloning and sequencing
(CoWin, Beijing, China). Sequence data from 16S rDNA fragments of $\mathrm{AOB}$ and $\mathrm{NOB}$ were submitted to NCBI (National Center for Biotechnology Information, USA) for homology searching.

\section{E. Real-time PCR: Quantification of Total Bacteria, AOB and $N O B$}

Quantification of the 16S rDNA gene of total bacteria was performed using the standard DNA (pGEM ${ }^{\circledR}-\mathrm{T}$ Vectors, Promega, Madison) possessing the 16S rDNA gene fragments of genomic DNA amplicons. As the fragment lengths of the vector and the inserted $16 \mathrm{~S}$ rDNA gene were known, the numbers of target DNA were directly calculated from the concentrations of the prepared plasmid. The concentrations of the standard DNA for total bacteria, AOB and NOB were adjusted as a series of 10 -fold dilution in the ranges of $5.8 \times 10^{6}$ to $5.8 \times 10^{11}$ (total bacteria), $5.8 \times 10^{4}$ to $5.8 \times 10^{9}$ (AOB and NOB $16 \mathrm{~S}$ rDNA) copies/gMLSS, respectively.

TABLE II. PRIMER CHARACTERISTICS AND CONDITIONS FOR NESTED PCR

\begin{tabular}{|c|c|c|}
\hline Primers & $\begin{array}{c}\text { Target } \\
\text { (specificity) }\end{array}$ & Sequence $\left(5^{\prime} \rightarrow 3^{\prime}\right)$ \\
\hline $\begin{array}{l}\text { CTO189fA/B } \\
\text { CTO189fC }\end{array}$ & \multirow{2}{*}{$\begin{array}{l}\text { 16S rRNA gene } \\
\text { (AOB) }\end{array}$} & $\begin{array}{l}\text { GGAGA(G)AAAGCAGGGGATCG } \\
\text { GGAGGAAAGTAGGGGATCG }\end{array}$ \\
\hline CTO654r & & CTAGCYTTGTAGTTTCAAACGC \\
\hline FGPS1269 & \multirow{2}{*}{$\begin{array}{l}\text { 16S rRNA gene } \\
\text { (NOB) }\end{array}$} & TTTTTTGAGATTTGCTAG \\
\hline FGPS872 & & CTAAAACTCAAAGGAATTGA \\
\hline F338-GC & \multirow[t]{2}{*}{$\begin{array}{l}\text { 16S rRNA gene } \\
\text { (Universal) }\end{array}$} & $\begin{array}{l}\text { CGCCCGCCGCGCCCCGCGCCCGGCCCG } \\
\text { CCGCCCCCGCCCCCTACGGGAGGCAG } \\
\text { CAG }\end{array}$ \\
\hline R518 & & ATTACCGCGGCTGCTGG \\
\hline
\end{tabular}

\section{RESUlTS AND DisCUSSION}

\section{A. IFAS Performance}

The operation and performance of IFAS has been described in our previous research [8]. Biofilm biomass worked alone on the first 40 days. Hybrid system was formed as soon as activated sludge was added into IFAS on day 41, and suspended sludge worked together with biofilm from then on. $\mathrm{NH}_{4}{ }^{+} \mathrm{-N}$ and $\mathrm{TN}$ removal efficiency were over $90 \%$ and $70 \%$ after day 80 , over $95 \%$ and $75 \%$ after day 120 . However, COD removal efficiency slowly elevated, and removal efficiency was merely $76 \%$ at the end of experience because of the non-biodegradable organics existed in influent. Effluent $\mathrm{COD}, \mathrm{NH}_{4}{ }^{+}-\mathrm{N}$ and $\mathrm{TN}$ concentration was $70.2 \mathrm{mg} / \mathrm{L}, 3.12 \mathrm{mg} / \mathrm{L}$ and $6.56 \mathrm{mg} / \mathrm{L}$ at the end of the experiment.

\section{B. DGGE Analysis: AOB Community Structure Changes in IFAS}

The well-resolved DGGE bands obtained at several representative points during the IFAS process revealed that the structure of the AOB communities was dynamic throughout the IFAS operation (Figure 1A).

In the DGGE gel image, each band corresponded to a unique species, and the density of each band was equivalent to the species abundance. The community structure at the end of experiment was different from that of the initial pattern of the seed sludge. The AOB communities in biofilm and suspended sludge showed $23.7 \%$ and $35.2 \%$ (calculated by Quantity One) 
similarity only to that in inoculated sludge indicating the considerable difference of AOB community structures between inoculated sludge, biofilm and suspended sludge. Though the dominant species in the inoculating sludge were preserved throughout the process (Figure 1A, bands a, b, g, h) and bands $\mathrm{g}, \mathrm{h}$ were very intense, many more bands were observed in biofilm (Figure 1A, bands i, m, n, k, o) and suspended sludge (Figure 1A, bands e, f, j) by day 80 compared to the seed sludge. The community structure of AOB did not change much in biofilm after suspended sludge was added into IFAS. This suggests that the biofilm AOB communities remained stable during the treatment process. Furthermore, the mild changes in the intensities of the bands indicated that the $\mathrm{AOB}$ communities changed slowly throughout the process.

The Shannon diversity index for each sample is shown in Figure 1B. The $H$ value was influenced by both the species number and species abundance. Major variations of $H$ occurred between day 100 and day 140, during which time the COD and TN removal efficiency decreased to $41 \%$ and $70 \%$. Concentration of influent COD and TN increased by $105 \%$ and $68 \%$ during this period due to the unstable influent which was provided by the wastewater treatment plant. AOB group was not suited to the changes in influent and the bacterial growth was inhibited. After a period of running, AOB group started to adapt to IFAS process conditions and be recovered gradually. $H$ values of sample $\mathrm{S}_{5}$ and $\mathrm{A}_{5}$ returned to 2.10 and 2.05 .

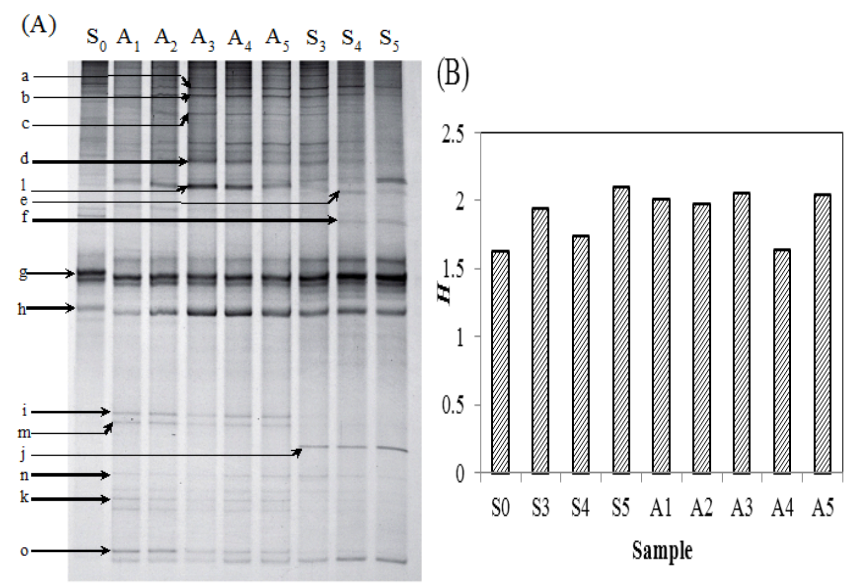

FIGURE I. (A)DGGE PROFILE OF AOB IN THE SUSPENDED SLUDGE AND BIOFILM SAMPLES; (B) CHANGE OF SHANNON DIVERSITY INDEX OF AOB POPULATION

\section{DGGE Analysis: NOB Community Structure Changes in IFAS}

Figure 2A shows the image of a DGGE gel of NOB PCR amplicons of the biofilm and suspended sludge samples taken from IFAS during whole operation. There were more common species both in suspended sludge and biofilm, including the populations represented by bands B, D, G, I, K and L. Among which, band $D$ and band $G$ were the top dominant species. Populations represented by bands $\mathrm{C}, \mathrm{E}, \mathrm{F}$ and $\mathrm{H}$ were dominant species and appeared across all suspended sludge samples and also increased in intensity gradually in biofilm samples as the experiment progressed. Most species were not inhibited by the increased loading rate between day 100 and day 140 , indicating that these species could adapt to the operating environment of IFAS.

DGGE analysis revealed that biofilm biomass contained a greater microbial diversity than that of suspended sludge. In biofilm, the diversity index increased remarkably from 1.90 to 2.33 on day 40 (Figure $2 \mathrm{~B}$ ). The microbial population then reached a relatively stable state. After day 80, the $H$ value of suspended sludge increased to 2.55 .

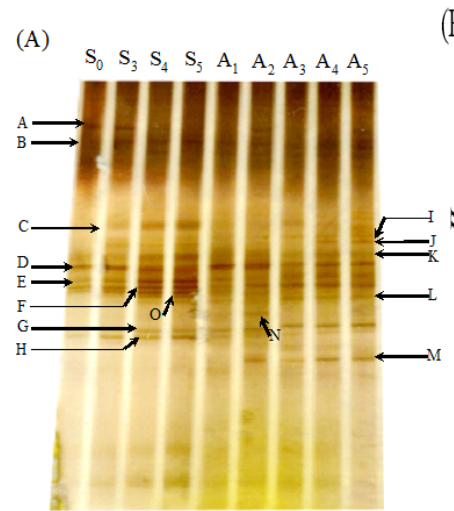

(B)

FIGURE II. (A) DGGE PROFILE OF NOB IN THE SUSPENDED SLUDGE AND BIOFILM SAMPLES; (B) CHANGE OF SHANNON DIVERSITY INDEX OF NOB POPULATION

\section{Sequencing Results}

Bands from the DGGE analysis were sequenced to determine the identity of bacterial strains present in the sludge (Table 3). All sequences were found to be $95-100 \%$ homologous with previously identified 16S rRNA gene sequences. As determined by comparison of the 16S rRNA sequences, the majority of the $\mathrm{AOB}$ and $\mathrm{NOB}$ bacteria grouped with members of Proteobacteria. Specifically, bands $\mathrm{g}, \mathrm{h}$ and o were closely related to ammonia-oxidizing lineages belonging to the b-subclass of the Proteobacteria. Nitrosomonas and Nitrosospira were also identified. Nitrosospira was unique AOB species in suspended sludge (band j). Band $\mathrm{c}$ is a widely present nitrifying bacterium in low ammonia aquatic surroundings. Band $\mathrm{E}$ had a similarity of 99\% with Pseudomonas sp. iCTE22 and belonged to $\gamma$ proteobacteria. Band $\mathrm{G}$ had a similarity of $100 \%$ with Nitrobacter sp. PBAB10 which was detected in the study of biofilm nitrification efficiency.

Many previous studies have debated whether Nitrosomonas or Nitrosospira is the more important ammoniaoxidizing bacteria in wastewater treatment systems $[4,6]$. In the current study, sequence analysis (Table 3) revealed that three dominant bands were closely related to betaproteobacterium, three was closely related to Nitrosomonas $s p$., while one was closely related to Nitrosospira sp. However, Nitrosomonas were the predominant species mainly in biofilm, while Nitrosospira sp. were the particular species in suspended sludge. Some members of Nitrosomonas sp. have been shown to produce more amounts of EPS (extracellular polymeric substance) than Nitrosospira, and these EPS are helpful to 
communicate cells with each other [9] and keep the biomass remained in the bio-carrier surfaces.

TABLE III. PRIMER CHARACTERISTICS AND CONDITIONS FOR NESTED PCR

\begin{tabular}{|c|c|c|c|}
\hline Bands & Number & Closest relatives & Identity \\
\hline a & AJ621026 & Nitrosomonas sp. Is79A3 & $96 \%$ \\
\hline b & AY123811 & Nitrosomonas sp. Nm59 & $100 \%$ \\
\hline c & DQ068712 & Uncultured AOB clone CL2-10/B & $95 \%$ \\
\hline g & AF266823 & $\begin{array}{c}\text { Uncultured beta-proteobacterium clone } \\
4.18 H\end{array}$ & $100 \%$ \\
\hline h & AF351233 & Uncultured beta-proteobacterium clone 4- & $99 \%$ \\
\hline j & AY189139 & Nitrosospira sp. CT2F & $98 \%$ \\
\hline l & AB000701 & Nitrosomonas sp. GH22 & $95 \%$ \\
\hline o & Z69160 & Beta-proteobacterium clone pH4.2A/D & $98 \%$ \\
\hline C & DQ128972 & Uncultured soil bacterium clone HSB & $100 \%$ \\
\hline D & AY135357 & Nitrite-oxidizing bicterium MPN2 & $98 \%$ \\
\hline E & DQ122322 & Pseudomonas sp. iCTE22 & $99 \%$ \\
\hline F & AY876628 & Uncultured Nitrospira sp. clone Nsp24 & $100 \%$ \\
\hline G & AY508475 & Nitrobacter sp. PBAB10 & $100 \%$ \\
\hline M & AM167975 & $\begin{array}{c}\text { Uncultured Nitrobacter } \text { sp. 16S rRNA } \\
\text { gene, clone VAS9 }\end{array}$ & $98 \%$ \\
\hline
\end{tabular}

E. Real-time PCR: Quantification of Total Bacteria, AOB and $N O B$

Quantitative real-time PCR was applied to estimate the abundance of total bacteria, AOB and NOB in suspended sludge and biofilm. The AOB 16S rRNA was present in greater numbers than the NOB in both of suspended sludge and biofilm (Figure 3 ). The copy numbers of AOB and NOB $16 \mathrm{~S}$ rRNA varied from $6.81 \times 10^{6}$ to $3.27 \times 10^{7}$ copies/gMLSS and $1.82 \times 10^{6}$ to $4.71 \times 10^{6}$ copies/gMLSS in suspended sludge, respectively. The values were $7.50 \times 10^{6}$ to $4.35 \times 10^{7}$ copies/gMLSS and $1.96 \times 10^{6}$ to $6.78 \times 10^{6}$ copies/gMLSS in biofilm. AOB and NOB numbers were related to the $\mathrm{NH}_{4}{ }^{+}-\mathrm{N}$ content of the influents, with higher $\mathrm{NH}_{4}{ }^{+}-\mathrm{N}$ contents corresponding to a higher $\mathrm{AOB}$ population in the sludge samples. The results were in agreement with other studies suggesting significant increases in AOB and NOB abundance in response to nitrogen fertilization [10].
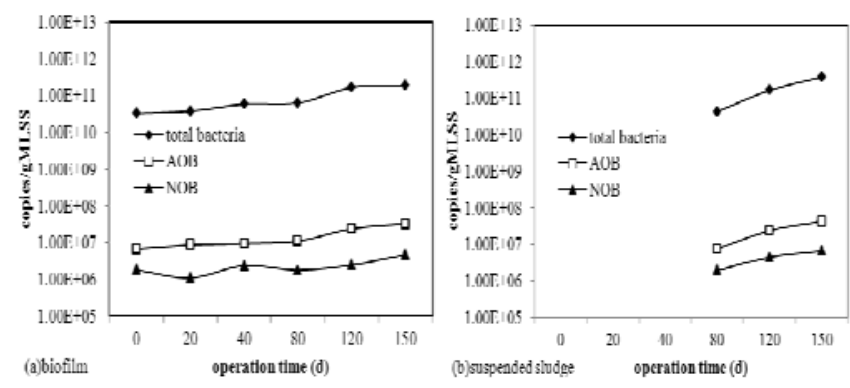

FIGURE III. VARIATION OF 16S RDNA COPIES OF AOB, NOB AND TOTAL BACTERIA IN IFAS

\section{CONCLUSIONS}

PCR-DGGE analysis of IFAS sludge samples showed that the dominant $\mathrm{AOB}$ and NOB species in suspended sludge and biofilm were different. However, the population dynamic succession was stable and less affected by the increased influent loading rate. DNA sequencing revealed that Nitrosospira sp. was the unique AOB species in suspended sludge, while Nitrite-oxidizing bacterium MPN2, Pseudomonas sp. and Nitrospira sp. clone Nsp24 were identified as dominant NOB population. Nitrosomonas sp. and $\beta$-Proteobacterium clone 4-70 were dominant AOB population in biofilm biomass, while Nitrobacter sp. clone VAS9 was identified as dominant NOB population.

This study has also suggested that there is a link between the diversity and quantity of $\mathrm{AOB}$ and $\mathrm{NOB}$ and the effluent quality from IFAS industrial wastewater treatment system. After activated sludge was inoculated, the changes of AOB and NOB community can improve nitrifying performance and maintain self-growth.

\section{REFERENCES}

[1] J. L. Wang, H. C. Shi, and Qian, Y, "Wastewater treatment in a hybrid biological reactor (HBR): effect of organic loading rates," Process. Biochem. vol. 36, pp. 297-303, 2000.

[2] J. G. He, J. Z. Li, J. S. Zhang, and Z. F. Pan, "Treatment of slaughter sewage with slime-activated sludge co-exist system,” J. Harbin Institute Technol. vol. 35, pp. 424-427, 2003.

[3] A. Cébron, M. Coci, J. Garnier, and H. J. Laanbroek, "Denaturing gradient gel electrophoretic analysis of ammonia-oxidizing bacterial community structure in the lower Seine River: impact of Paris wastewater effluent," Appl. Environ. Microbiol. vol. 70, pp. 6726-6737, 2004.

[4] U. Purkhold, A. Pommerening-Röser, S. Juretschko, M. C. Schmid, and M. Wagner, "Phylogeny of all recognized species of ammonia oxidizers based on comparative 16S rRNA and amoA sequence analysis: implications formolecular diversity surveys," Appl. Environ. Microbiol. vol. 66, pp. 5368-5382, 2000.

[5] S. Q. Xia, J. Y. Li, and R. C. Wang, "Nitrogen removal performance and microbial community structure dynamics response to carbon nitrogen ratio in a compact suspended carrier biofilm reactor," Ecol. Eng. vol. 32, pp. 256-262, 2008

[6] S. Okabe, H. Satoh, and Y. Watanabe, "In situ analysis of nitrifying biofilms as determined by in situ hybridization and the use of microsensors,". Appl. Environ. Microbiol. vol. 65, pp. 3182-3191, 1999.

[7] J. B. Guo, F. Ma, C. C. Chang, D. Cui, L. Wang, J. X. Yang, and L. Wang, "Start-up of a two-stage bioaugmented anoxic-oxic (A/O) biofilm process treating petrochemical wastewater under different DO concentrations," Bioresource Technol. vol. 100, pp. 3483-3488, 2009

[8] C. Li, X. L. Li, M. Ji, and J. Liu, "Performance and microbial characteristics of integrated fixed-film activated sludge system treating industrial wastewater," Water Sci. Technol. vol. 66, pp. 2785-2792,2012.

[9] S. S. Adav, D. J. Lee, and K. Y. Show, "Aerobic granular sludge: recent advances,” Biotechnol. Adv. vol. 26, pp. 411-423, 2008.

[10] B. Zhang, B. S. Sun, M. Ji, H. N. Liu, and X. H. Liu, "Quantification and comparison of ammonia-oxidizing bacterial communities in MBRs treating various types of wastewater," Bioresource Technol. vol. 101, pp. 3054-3059, 2010. 